\title{
Autonomous maritime operations and the influence of situational awareness within maritime navigation
}

\author{
Jevon P. Chan ${ }^{1}$ (1) $\cdot$ Rose Norman $^{1} \cdot$ Kayvan Pazouki $^{1} \cdot$ David Golightly $^{1}$
}

Received: 15 January 2021 / Accepted: 28 January 2022 / Published online: 2 March 2022

(c) The Author(s) 2022

\begin{abstract}
As the maritime industry looks to implement autonomous operations, it is key that seafarers can adjust and work alongside the technological strides being made. With the maritime industry being on the brink of a paradigm shift, not seen since the transition from sails to engines, regulations and training need to be implemented before the industry can progress towards autonomous vessel operations. Therefore, the maritime industry must implement methods and training regimes that seafarers can undertake to train skills such as situational awareness, to ensure that the humanautomation relationship progresses smoothly and efficiently. The research reported within this paper aims to assess the elements required to aid the development of seafarers, in preparation for the inevitable change to autonomous maritime operations. A study was conducted which analysed the situational awareness of 14 junior navigational officers and 14 navigational officer cadets, by means of a bridge watch simulator and introducing the participants to an autopilot failure. The results of the study found a lack of system understanding, in the event of a fault, among the majority of participants. Additionally, even the participants displaying a satisfactory level of situational awareness required alarms before they could recognise a potential fault. Additionally, participants were given a survey which allowed the assessment of their personal views and opinions of autonomous operations. By assessing the outcome of this study and researching past maritime incidents, this paper has highlighted the necessity for situational awareness training for seafarers which will improve the human automation relationship.
\end{abstract}

Keywords Human factors · Autonomous shipping · Situational awareness · Autonomous maritime operations $\cdot$ Human error

Jevon P. Chan

j.chan4@newcastle.ac.uk

1 Newcastle University, Newcastle upon Tyne, UK 


\section{Introduction}

Technological advancement is the aim for all transportation industries, and it is key that each sector remains up to date with the direction in which the digitisation of technology is taking them. In regard to shipping, the maritime industry is arguably facing its greatest technological transition since the introduction of the diesel engine, in the development of autonomous operation. With the levels of automated operations gradually increasing in recent years, maritime vessel operations are steadily approaching a point where autonomous operations can be incorporated among various fleets of merchant ships. This trajectory towards autonomous operations has been highlighted with research conducted through theoretical projects, autonomous ship building projects and the development of autonomous vessel regulations. Projects such as the Maritime Unmanned Navigations through Intelligence in Network (MUNIN) (MUNIN 2017) and Advanced Autonomous Waterborne Applications (AAWA) (Jokioinen 2016) have given the maritime industry knowledge towards the installation and production of autonomous systems, whereas projects such as the Autonomous Shipping Initiative for European Waters (AUTOSHIP) (Bolbot et al. 2020), DNV GL ReVolt project (DNV GL 2017) and Yara Birkeland (Kongsberg 2017) have allowed for the development of autonomous ships on a small scale. As a result, by combining these projects with the development of various autonomous vessel regulations and sea trials such as IMO MSC scoping exercise on Maritime Autonomous Surface Ships (MASS) (MSC - IMO 2018) and Nippon Yusen Kaisha (NYK) line crewless MASS trials (NYK Line 2019), the introduction of autonomous vessel operations is close at hand.

The overall work life of seafarers is in a much higher risk bracket than that of working on land. Research has shown that merchant seafaring is one of the most dangerous occupations and, due to the nature of the hazardous work conducted, it is often associated with suicide, homicide and danger to human life (Roberts et al. 2014). The introduction of autonomous technology to maritime operations has the potential to reduce the risk to human life considerably, by reducing the element of human associated accidents on board (Jokioinen 2016). The overall benefits to autonomous vessel operations have been publicised and highlighted, from eliminating human error, to reducing the overall crew costs, increasing the safety of life of seafarers and improving efficiency with respect to vessel design and fuel consumption. The European Maritime Safety Agency [EMSA] reported that from 2011 to 2018, 65.8\% of accident events were attributable to human action (EMSA 2019). Furthermore, from the maritime accidents accounted for by human action, the main factors which contributed to the accidents were inadequate work methods and safety awareness. However, when assessing for cargo and passenger ships individually, the EMSA reported that $68.6 \%$ and $58.9 \%$ of accidents were attributed to human action, respectively. Moreover, the second most significant contributing factor to maritime accidents was system/equipment failure with $20 \%$ being the cause of the incident. Again, when assessing vessels individually, it was reported that $16.2 \%$ and $29 \%$ of accidents were attributed to cargo ships and passenger vessels respectively (EMSA 2019). With such a significant percentage of maritime accidents being attributed to 
human action, the argument for crewless vessels is strengthening. However, with $20 \%$ of accidents being caused by a system malfunction, autonomous vessel operations and automated systems could be fallible. Therefore, without further research and evidence on crew training standards, no definitive argument can be made regarding the complete removal of seafarers on ships. Furthermore, due to the juvenile state of autonomous operations and the transition from the current status to full autonomy, seafarers will need to be factored into the decisions on autonomous operations for the foreseeable future.

With vessel navigation among seagoing vessels steadily transitioning from the 1 st degree of autonomy "crewed ship with automated processes and decision support" to the 2nd degree "remotely controlled ship with seafarers on board", as per the regulatory scoping exercise conducted by the IMO (MSC - IMO 2018), it is imperative that the navigational officers have an in depth understanding, not only of how to operate the system, but also how to pre-empt any potential incident which may occur. However, past accidents such as the grounding of the Lauren Hansen and the grounding of the Priscilla have shown that even with sufficient prompting and maritime notice, human operators are still susceptible to a degradation of situational awareness and ultimately display key characteristics of showing bias towards the automated system over their own judgement and training (ATSB 2018) (MAIB 2019).

The aim of this study is to assess the elements required to aid the development of seafarers in preparation for the change to autonomous maritime operations. In this paper, 28 participants, varying in rank, age, length of time spent at sea and degree of education, were chosen to perform two unique simulator exercises and a follow-up survey. The aim of the physical experiments was to assess each participant's bridge watch procedure and ultimately how they reacted to a subtle fault in the navigational systems and if they displayed signs of an acute sense of situational awareness. Subsequently, the survey was conducted to gain an understanding of the views that junior officers and young seafarers have regarding the introduction of autonomous shipping.

The overall structure of the paper consists of a section highlighting the literature that has aided this design of the exercises, by emphasising both human factors and the use of simulation for maritime training. Following the literature section, the paper then discusses how both experiments of the study were designed and constructed with the paper then analysing the results of the study, before concluding and assessing future work for this area of research.

\section{Maritime human factors and simulation}

Within the maritime industry, human factors are often referred to as the interaction between humans and machines at sea (Schröder-Hinrichs et al. 2013). With a significant number of accidents annually being attributed to human error, it is important to understand the main causes behind the accidents and how elements such as situational awareness, automation bias, complacency and other human actions factor 
into the incident. Education through the use of simulation training may possibly aid with the understanding of maritime autonomy.

\subsection{Situational awareness, automation bias and complacency}

The term situational awareness can be defined as how elements are viewed within their surroundings, relative to time and space, and how to foresee or predict the occurrence of events by understanding trends and patterns (Endsley 1995). As the transition towards autonomous vessel operations begins to advance, the situational awareness of the system operator is key. Thus, as time constrained events, such as potential vessel incidents progress, it is imperative that the system operator has the knowledge and understanding to be able to assess and, if required, correct any malfunction or abnormal behaviour elicited by the system. Due to the high technical level of autonomy, it would be easy for an operator's situational awareness to begin to degrade over time and for the operator to ultimately become complacent under autonomous operation. Should the autonomous system degrade or lose its reliability, the officer's situational awareness should not be negatively affected allowing them to correct the fault. However, should an officer's situational awareness begin to degrade, it will result in a slower reaction time in fault detection which will have a resultant impact on the individual's reorientation time with regard to their current situation and system parameters (Gombolay et al. 2017).

Automation bias can occur due to the uncertainty of the operator, resulting in the operator beginning to search for evidence to justify their decision-making. Poor decision-making can occur when the system malfunctions to a level where the human operator begins to trust the system against their own knowledge, judgement and understanding of the situation (Parasuraman \& Manzey 2010). As autonomous operations become a mainstay within the maritime industry, human operators may begin to display signs that they unconditionally trust the system as it will be assumed to be reliable. With the addition of decision aiding systems to reduce human error, the level of trust displayed by an operator may be so powerful that it overrides their sense of judgement and acknowledgement of surrounding information; this can be defined as automation bias (Skitka, et al. 1999).

With autonomous technology aiming to reduce the human error in incidents, maritime officers may become accustomed to a much slower paced working environment than they are currently experiencing. Consequently, the day-to-day operations of the wheelhouse may become far more mundane and monotonous (Schuffel et al. 1989), introducing a potential risk of automation complacency. Furthermore, with seafarers being subjected to a slower paced working environment, research has shown that there are fundamental problems with monitoring and a work underload which ultimately results in a difficulty in vigilance retention (Young \& Stanton 2002). Automation complacency can be defined as degradation in how an operator effectively observes the situation; The operator begins to make assumptions about the reliability of the system, thus degrading their own knowledge and expertise (Mosier et al. 2013). 
With highly publicised incidents such as the grounding of the vessels Priscilla, Ruyter, Lauren Hansen and Costa Concordia, it is apparent that no sector of merchant shipping is excluded from human error and that even with sufficient prompting human operators are still susceptible to a degradation of situational awareness and ultimately display key characteristics of automation bias. Additionally, it can be seen from the sequential failures that the incidents could likely have been avoided if an increased level of situational awareness had been displayed (MAIB 2019) (MAIB 2017) (ATSB 2018) (MIT - Marine Casualties Investigative Body 2012). As the maritime industry transitions from one level of autonomous operation to the next, seafarers will need to cope with changes to their working environment and have a detailed understanding not only of how to operate the systems, but also how to preempt incidents which may occur due to incorrect operational procedures.

\subsection{Utilisation of simulation in maritime transportation}

The first maritime simulator was designed for research purposes in 1967, in Göteborg Sweden, with the aim to give the maritime industry a better understanding of crew behaviour, ship designs and port designs (Eda et al. 1996). Subsequently, the design of fully immersive wheelhouse simulators has enhanced the education of seafarers.

Simulators are extensively used within various sectors of the transportation industry, such as aviation, rail and automotive. It has been widely accepted that simulators aid in the training of pilots and allow them to gain a greater understanding of how to conduct themselves should a dangerous situation arise. A recent aviation simulator study analysed how pilots reacted in the event of an unexpected malfunction and found that the utilisation of a variable and unpredictable training approach benefitted pilots in their fault recognition abilities (Landman et al. 2018). With simulators being a key tool in the development of transportation human factors, it is paramount that the maritime industry learns from the obstacles overcome by more advanced transportation simulators. As with all technology there are benefits and drawbacks. However, as can be seen in Table 1, which has been adapted from the information displayed in literature, the advantages of utilising maritime simulation far outweigh the limitations (Lützhöft et al. 2017).

\section{Methodology}

In this study, 28 participants who varied in rank, seagoing experience, degree of education and age were selected to participate in 2 different physical simulator exercises and a subsequent follow-up survey. Of the 28 participants, 14 were fully qualified officers enrolled in the Chief Mates preparation course at the maritime facility, whereas the other 14 were final phase navigational cadets. The physical simulator exercises replicated the environment of a functional merchant vessels wheelhouse and assessed each participant's bridge watch procedure and how they reacted to a subtle malfunction within the navigational system. Moreover, the follow-up survey 


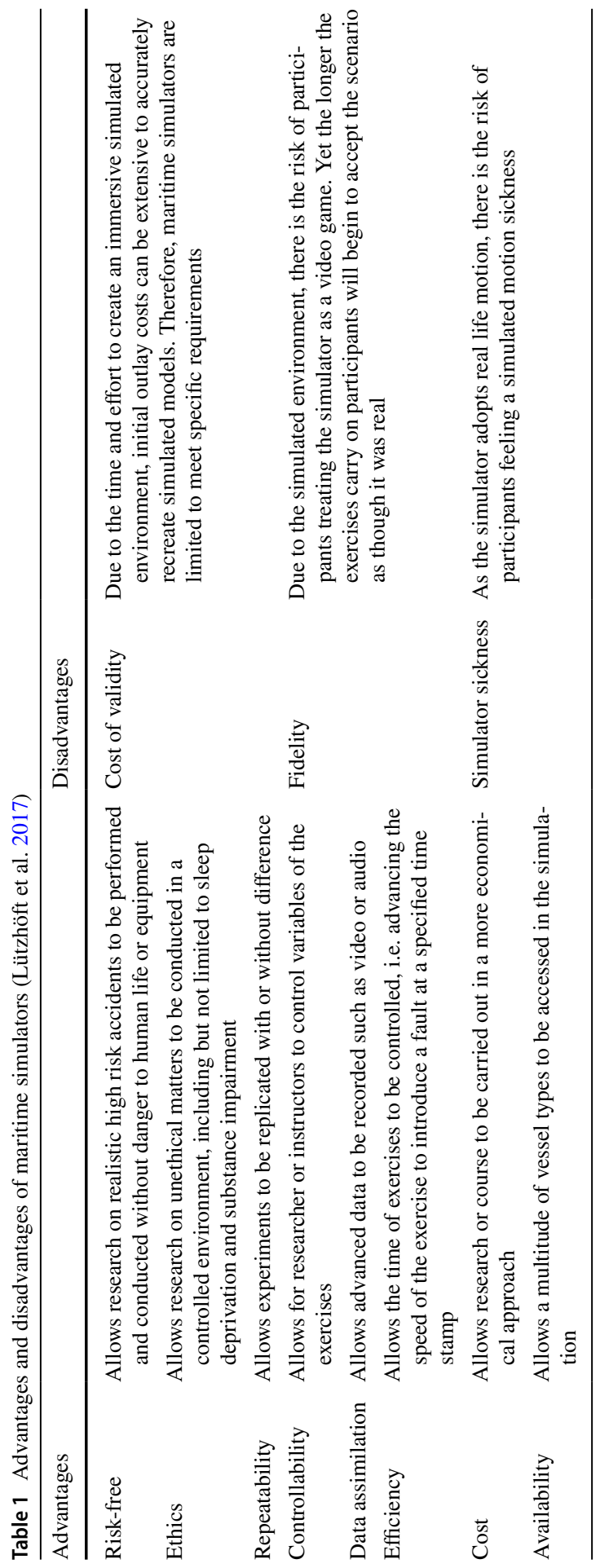


assessed the thoughts of junior maritime officers and young seafarers, who will likely be involved in the transition towards autonomous shipping, regarding the introduction of autonomous vessel operations.

It was essential that the participants met the minimum requirements of 12 months of seagoing experience as part of the navigational bridge crew. Therefore, the minimum rank which could be analysed for this study was that of a final phase navigational cadet. However, other variables such as age and degree of education differed between candidates to allow further analysis of the test results. All of the participants in this study were due to be promoted within the months succeeding this study. Hence, final phase navigational cadet participants would be qualified junior officers, and junior officers would be promoted to chief mates.

\subsection{Experimental procedure}

The aim of the physical experiment was to assess if automated navigational systems, deemed highly reliable by seafarers and the maritime industry, and provide the trained operator with a significant amount of reassurance, such that should the system begins to fail, it would go unnoticed by the operator. At the preliminary stages of the research, various system faults were considered; however, it was decided that the best way to assess a participant's fault recognition would be to introduce a subtle fault in a system which they would consider reliable. In this instance, the fault would be introduced through the autopilot. During the initial research stage, it was also decided that the test scenario should be a user-controlled test vessel in a large body of water away from high traffic areas and land to ensure that it was realistic and also to ensure that the participants were not overwhelmed by the transpiring events. Additionally, to recreate an immersive experimental environment, it was also key that the participant felt as though they were carrying out part of a bridge watch. Hence, a work pack was designed with various quizzes, a ship particular worksheet and logbook which simulated the participant being distracted by menial paperwork tasks, similar to those completed by seafarers during a navigational watch. The issuing of the work pack was to analyse the participant's prioritisation of their work, i.e. the emphasis placed on completing the work pack versus the concentration given to ensure that the watch is as safe as possible. Once the experiment had been designed, a pilot study was conducted, and the resultant data was analysed. The key objective of the physical experiment was to understand if the onboard autopilot system affects the judgement of the participant, with regard to their ability to conduct a safe navigational watch as per the requirements of MGN 315 (MCA 2006).

The physical test was conducted in a fully interactive bridge simulator, modelled from a standard bridge wheelhouse setup. The setup of the simulator consisted of a standard bridge control panel fitted with a variety of bridge monitoring and control systems, including but not limited to a remote steering module, magnetic compass, electronic chart display information system (ECDIS), engine order telegraph, $360^{\circ}$ viewing controls and port and starboard radar displays. Additionally, the simulator suite contained a main steering column and a chart workstation which housed the controls for the vessels fire and general alarm systems. In addition to the systems, 
the simulator suite also housed 3 screens at the front of the simulator positioned to give the participant a $120^{\circ}$ view of their virtual environment, and a single screen positioned behind the main steering column which allowed the participant to view the events happening behind them.

A Panamax bulk carrier was selected to be the test vessel for the physical experiment which was conducted using the Kongsberg Polaris simulator software and Seaview R5 visual software. The overall experiment consisted of two similar scenarios with the vessel being operated in the daytime, surrounded by low vessel traffic and in a position where the participant may feel compelled to alter the vessels course. However, the main difference between the two exercises is that there are key events which are unique to each scenario, one being that the vessel undergoes routine fire alarm testing throughout the exercise and the other being that the vessel experiences a course deviation. The traffic vessel parameters for both exercises are shown in Table 2. To ensure that the participants understood the purpose of the experiment and were content with the operational parameters of the simulator suite, all participants were given a mission brief prior to beginning the experiment. During the mission brief, all participants were given bridge simulator familiarisation, consisting of how to operate all systems within the simulator. The mission brief allowed the participant to develop a level of trust in the system by understanding how the simulator operated.

Participants were given sufficient opportunities to correct any fault which they encountered both aurally, through the clicking of the magnetic compass and alarms ringing, and visually, such as cloud patterns moving and vessels deviating from traffic positions. Throughout the exercises, the participants had full communication access to the control station, which they could use if they began to encounter difficulties. Additionally, every participant was monitored using CCTV and microphones which were active throughout each exercise. For each participant, a watch handover was conducted during the mission brief. The handover consisted of telling the participants about the ship's position, traffic density and the weather conditions. Throughout the entire physical testing phase, the participant was the only person present in the simulator suite, unless they requested the presence of a look out.

For both exercises, the participant entered the simulator suite to find the test vessel travelling on a course heading of 000 at a speed of 14 knots. In each case, the participants were subjected to a scenario exclusive to that exercise. The exercise commenced once the participant was familiar with the layout of the simulator suite.

Table 2 Traffic vessel parameters

\begin{tabular}{lllllll}
\hline Exercise & Vessel & Ship type & $\begin{array}{l}\text { Starting dis- } \\
\text { tance }[\mathrm{nm}]\end{array}$ & Bearing $\left[^{\circ}\right]$ & Speed [knots] & Heading $\left[^{\circ}\right.$ ] \\
\hline A & 001 & Tanker & 3 & 245 & 18 & 330 \\
& 002 & Ro-Ro & 4 & 015 & 12 & 180 \\
& 003 & Container & 12 & 345 & 24 & 090 \\
B & 001 & Bulk carrier & 5 & 180 & 13 & 35 \\
& 002 & Ro-Ro & 10 & 215 & 18 & 080 \\
\hline
\end{tabular}


For exercise A, participants would enter the simulator suite to find the traffic vessel parameters described in Table 1 within close proximity to their ship. When the exercise commenced, the participant would be able to alter the position to ensure that the closest point of approach (CPA) to the oncoming vessel would exceed 1 nautical mile. As the test vessel passes the CPA of the oncoming vessel, the test ship would then begin to experience a gyro drift failure. Due to the malfunctioning gyro, the vessel will begin to follow a changing heading dictated by the gyro while displaying a 000 degree heading to the participant. If the simulation is left unaltered by the participant, an off track alarm will begin to sound indicating that the vessel has travelled 20 degrees from its intended course; this alarm is the final prompt for the participant to correct the fault. The exercise was conducted over a 20-min period; hence, participants who were unsuccessful in recognising the fault were given a time score of $660 \mathrm{~s}$, the time from the initiation of the fault to the end of the exercise.

In exercise $\mathrm{B}$, the participant would encounter a fire alarm, within zone 1 of the vessel at precisely $90 \mathrm{~s}$ from the start of the exercise. The sounding of the alarm should then prompt the participant to contact the captain, where they would then be told that throughout the exercise routine, fire alarm testing would occur in every zone of the vessel. The fire alarms would then begin to sound at 90-s intervals, distracting the participant from focusing on either their paperwork or the events transpiring on the water. During exercise B, participants did not experience a course alteration or navigational system malfunction. Therefore, should the vessel's course be left untouched throughout the exercise the course heading would remain at 000 degrees.

\subsection{Maritime officer survey}

The aim of conducting the maritime officer survey was to gain an understanding of the mindset of junior officers and assess their own self-judgement of their trust in autonomy. Therefore, it was disseminated to the same 28 participants as a part of the debrief for the study. The design of the survey allowed the participant to answer without showing bias to either side of the argument. The overall survey was structured to contain 20 individual sections; in Sects. 1 to 17, the survey assesses the demographic information of the individual, including previous seagoing experience. Once the participant has completed the background information, they were presented with various questions to provoke a response from the participant. The questions required the participant to express their views on autonomy, their past experiences with automated systems and their trust in automated systems. Within this study the questions that were analysed focused on the participant's trust in automated systems and to discover if the participant had any further training beyond what is mandatory as per the minimum requirements of STCW Certificates and Requirements for Officer in Charge of a Navigational Watch on Ocean Going \& Near Coastal Ships (MCA 2015).

The questions used in the questionnaire were structured under the 2 following question types: 
- Likert scale: questions designed to invoke a response from the participant indicating the how strongly they feel regarding the discussed topic in the question (Brown 2011).

- Subjective dichotomous: questions which give the participant a small answer pool (Batchelder \& Narens 1977)

The Likert scale questions asked were a given a standard 5-point Likert scale answering method, with 5 being "highly agree" and 1 being "highly disagree". The aim of using the 5-point Likert scale was to allow the participants to answer the question whilst maintaining a midpoint, so if they felt indifferent to the question, they were not forced to favour one argument side over the other (Chyung et al. 2017). The key questions which delivered the analysis of the seafarers' perspective towards autonomous maritime operations are shown in Table 3.

\section{Analysis}

All results were recorded for analysis, from both the simulator exercises and the maritime officer survey. The results analysed were comprised of the following: the order in which the exercises were conducted, age group of the participant, participant rank, fault recognition time, volume of paperwork completed and seafaring experience. Additionally, the results from the survey were organised into the following categories: alarm management training, alarms aid my situational awareness and perceived level of trust in automated system. Table 4 displays the results gathered from the study. The participants who successfully reacted to the fault were considered to have an acute sense of situational awareness throughout the exercises. Conversely, the participants who failed to react to the fault have been classified to display a lack of situational awareness; thus, participants were labelled to be "accurate" or "inaccurate" to indicate their success in identifying the fault respectively. It should also be noted that the survey responses displayed in Table 4 correlate to the questions posed in Table 3, with a participants "level of trust" being an average of the participants' responses to questions 1 and 2 from Table 3.

The simulator suite included CCTV and a microphone to allow the instructor to monitor each participant visually and audibly. The results were processed and displayed in a manner where the participant would have a reaction time for Exercise $A$ - Gyro Drift, which was calculated in seconds from the start of the system malfunction, $0 \mathrm{~s}$, to the second that the participant reacted to the malfunction. At precisely $414 \mathrm{~s}$ into the exercise, the off track alarm would sound indicating that the vessel has deviated from its intended course, providing that the participant had not altered the vessel heading. However, should the participant fail to react, within the 20 -min exercise, they would be given a reaction time of $660 \mathrm{~s}$. Analysis of the results from the study was conducted by categorising the participants into Group A and Group B based on the order in which they completed the exercises, with Group A completing Exercise B - Fire Alarm first and then Exercise A - Gyro Drift and Group B completing the exercises in the reverse order. 


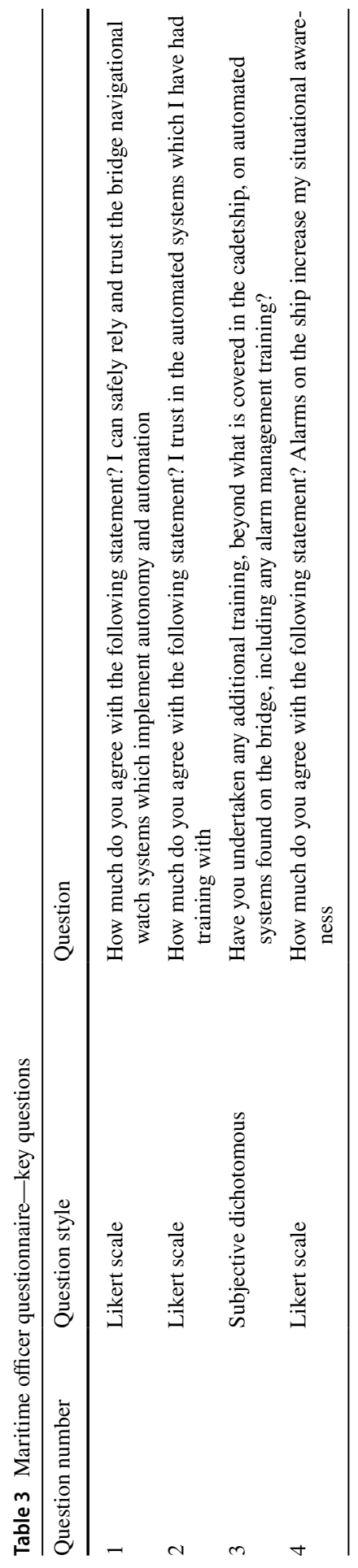




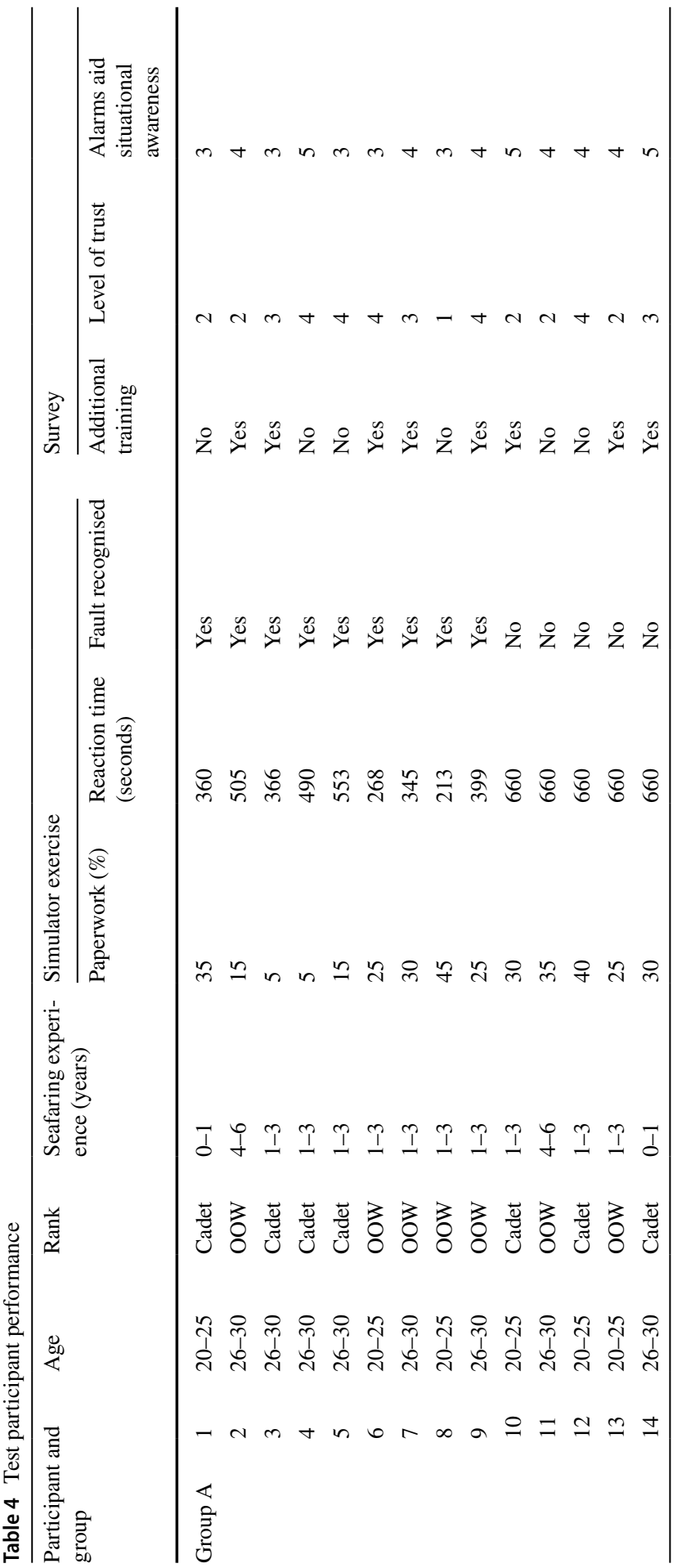




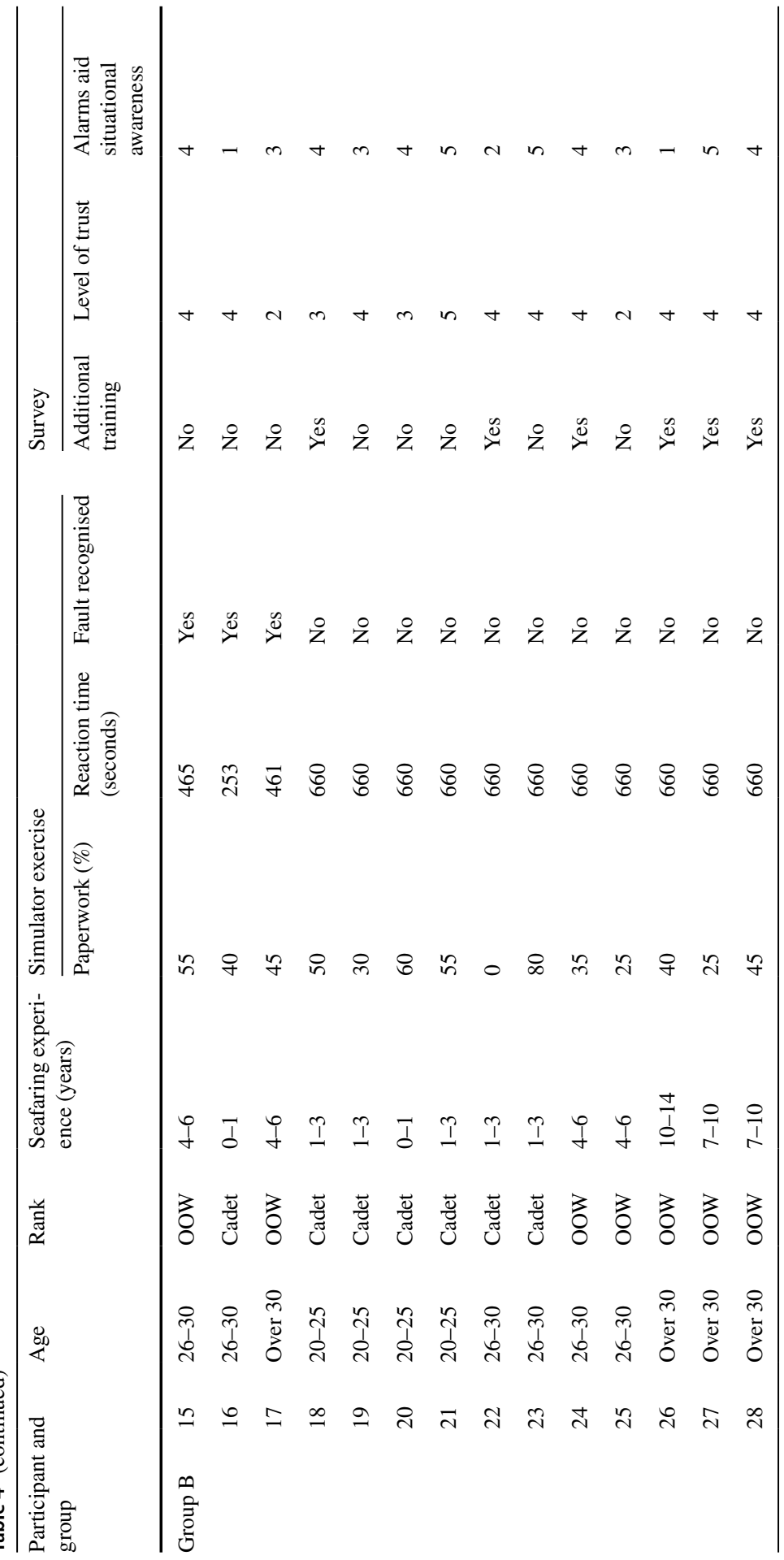




\subsection{Simulator exercises}

With the exercises having been setup to operate under the control of an individual participant, this allowed behavioural observations to be made for each participant. All participants were given the same information; however, this did not stop each participant taking a unique approach to the exercises. Some participants would primarily focus on the paperwork as they may have viewed it, as necessary. However, by concentrating on the paperwork, participants would often fail to react to the course deviation. This hypothesis can be verified as it can be seen in Table 4 that all participants, except for one, who completed over $50 \%$ of their paperwork failed to react to the system fault. Additionally, it should be noted that the participant who did react to the fault only did so after the sounding of the off track alarm, at $414 \mathrm{~s}$. Beyond the paperwork, participants would begin to display signs of boredom and restlessness by yawning, checking their watch and checking their phones. Additionally, Fig. 1 shows how both groups performed throughout the exercises. The fastest reaction time, of $213 \mathrm{~s}$, belonged to a participant from Group $A$, whereas the fastest reaction time from a participant in Group B was 253 s. Furthermore, Group $A$ had far more successful attempts, with 9 participants successfully reacting to the fault, compared to Group $B$ which had 3 participants reacting to the fault.

As shown in Fig. 1, Group A on average was faster at reacting to the gyro drift fault. However, due to the limited pool size of successful participants for Group $B$, assessing slowest, fastest and median reaction times was more suitable. As can be seen in Fig. 1, the overall fastest fault recognition time belonged to Group A as did the quicker median time. Conversely, the faster slowest time belonged to Group B.

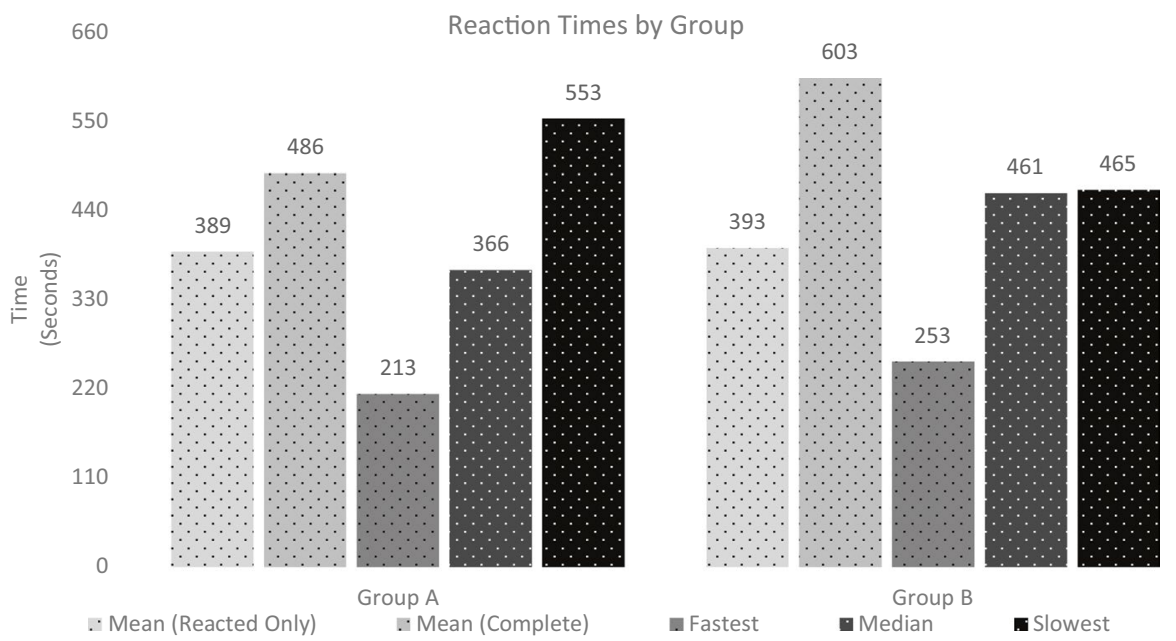

Fig. 1 Participant fault recognition times by group 


\subsection{Maritime officer survey}

As shown in Table 5, participants on average favoured an "on the fence" to "slight agreement" response when asked about their level of trust in autonomy and if alarms aided their situational awareness. However, when broken down into their groups, participants with an inaccurate level of situational awareness from Group A claimed to have a lack of trust in autonomous systems and were strongly in favour of the statement that alarms aided situational awareness. This possibly highlights a lack of knowledge about autonomy among the participants, as their responses contradict their actions from the simulator exercises where they had failed to react appropriately when signalled by the alarm system. Conversely, participants displaying an accurate level of situational awareness from Group B only slightly favoured their trust in autonomy and disagreed that alarms aided situational awareness. This again contradicts their actions in the simulator exercises as all, but 1 participant deemed "accurate" in Group B required the aid of an alarm at 414 s to recognize a fault.

Within the survey, participants were questioned as to whether they had undertaken additional automated system training, beyond what is covered in the Merchant Navy Training Board (MNTB) cadetship programme. As seen in Fig. 2, the number of participants who had not completed further training was equal for participants displaying accurate and inaccurate situational awareness. Conversely, the number of participants who displayed accurate situational awareness and had undertaken additional training was lower than the participants who had displayed inaccurate situational awareness yet had undertaken further training with 5 and 9 participants, respectively.

\section{Discussion}

\subsection{Limitations of autonomy}

With the direction of the maritime industry tending towards autonomous operations, similar studies have been conducted using small sample pools (Pazouki et al. 2018). It was crucial for this study that the number of participants was higher, but also that they had a greater knowledge and seafaring experience than those in the previous study. Therefore, the participant pool needed to incorporate a wider diversity of

Table 5 Participants survey response table of means

\begin{tabular}{|c|c|c|c|c|c|c|c|}
\hline \multirow[t]{3}{*}{ Groups $n=28$} & \multicolumn{7}{|c|}{ Situational awareness level } \\
\hline & \multicolumn{3}{|l|}{ Accurate } & \multicolumn{3}{|c|}{ Inaccurate } & \multirow[t]{2}{*}{ Complete } \\
\hline & Group A & Group B & Total & Group A & Group B & Total & \\
\hline Level of trust in automation & 3.000 & 3.333 & 3.083 & 2.600 & 3.727 & 3.375 & 3.250 \\
\hline $\begin{array}{l}\text { Do alarms aid situational aware- } \\
\text { ness? }\end{array}$ & 3.556 & 2.667 & 3.333 & 4.400 & 3.636 & 3.875 & 3.296 \\
\hline
\end{tabular}




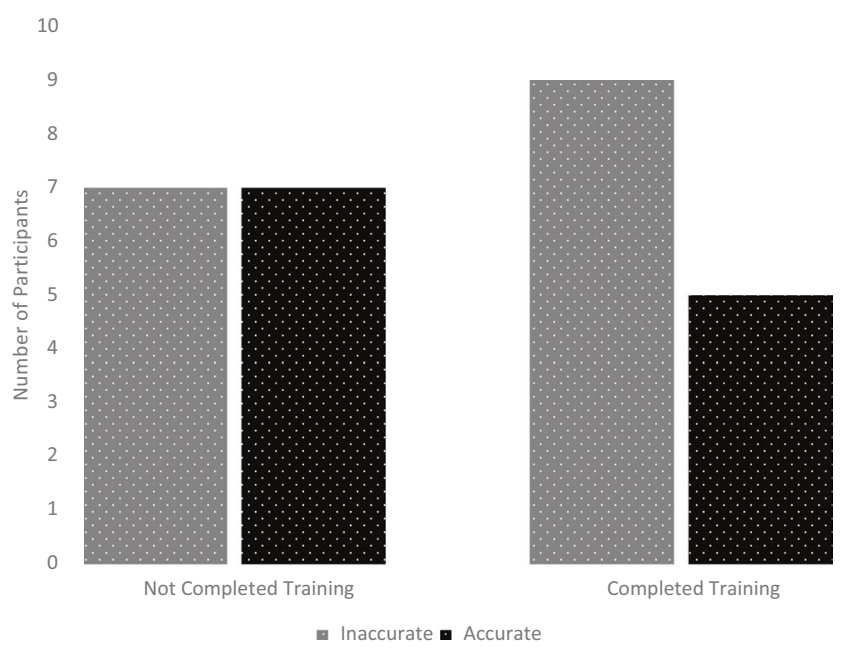

Fig. 2 Additional automated training versus level of fault recognition displayed

participants. From the 28 participants assessed, less than $50 \%$ successfully reacted to the course deviation. However, it may be argued that if the participants were given a longer period of time to acknowledge the fault, then more participants could have recognised it and reacted accordingly. Furthermore, when analysing the groups individually, it can be seen that Group A produced a higher quantity of successful reactions than Group B. However, it may be argued that the justification for Group $A$ performing so well may be that they were in a higher state of alertness than Group $B$ due to having completed the fire alarm exercise prior to undergoing the gyro drift exercise.

When presented with the post exercise survey, candidates showed an uncertainty in their responses. The survey was delivered to the participants to gain a greater understanding of the viewpoints that officers and cadets have towards autonomy and situational awareness aids. However, as shown in Table 5, candidates only slightly agreed with both sentiments of "I can trust automated and autonomous systems" and "Alarms aid situational awareness". This was further confused by the participants who claimed that alarms aid their situational awareness and yet failed to identify a navigational fault in the gyro drift exercise when their vessel sounded the off track alarm.

In addition to the gyro displaying a fault on the vessel's radar, the participants would have also seen that the indicator read the same heading, indicating that there was nothing wrong with the course which the vessel was undertaking. The majority of participants completed their work packages following the successful passage of the oncoming vessel, only briefly looking at the radar to validate their actions and trusting that the autopilot system was operating correctly. Thus, the participants became vulnerable to suffering from automation complacency, defined as a degradation of human detection for automated system malfunctions (Parasuraman and Manzey 2010). 
Of the 12 participants who successfully reacted to the course alteration, only 7 reacted to the fault prior to the sounding of the off track autopilot alarm. Among the participants who reacted successfully, a common trait was to change the control of the vessel to manual operation, correct the course and then turn the control of the vessel back to the ship's autopilot. As seen in the case of the grounding of the Lauren Hansen, if a fault with the vessel's autopilot system is overlooked or not repaired, then the consequences could result in an incident as serious as the vessel running aground or worse (ATSB 2018). The ship's autopilot and navigational systems only operate as efficiently as the operator in control of the system.

\subsection{Improving the human-automation relationship}

From potentially reducing the environmental impact of maritime operations to optimising the route planning and course of the vessel, research has made the benefits of moving towards autonomous vessel operations apparent (Kretschmann et al. 2017). However, from an ethical perspective, fully unmanned autonomous vessel operations may be a future obstacle for the maritime industry to address (Kim et al. 2020). Therefore, in the foreseeable future, the human operator must have trust in the systems, yet also have the situational awareness and knowledge to assess and prevent any incidents from occurring.

From the participants analysed, the variation in alertness and situational awareness differed greatly. Research conducted on situational awareness has shown that it is a skill, which with sufficient training can be enhanced. Various techniques such as being mindful of the environment and staying vigilant allow individuals to improve their situational awareness (Gregory et al. 2015). Beyond self-improvement, the maritime industry could introduce short courses that operators may undertake to improve their situational awareness. Similar courses, which may serve as a foundation for the development of a situational awareness short course, currently exist. The navigational aids, equipment and simulation training (NAEST) is comprised of 2 levels: operational and management. The NAEST management course allows the individual to undertake fully immersive training for the competent use of navigational systems onboard vessels, and, as per the requirements of the MCA, navigational officers must complete this course prior to their qualification as chief mate (MCA 2019). From the participants who displayed accurate situational awareness, the fastest reaction time of $213 \mathrm{~s}$ belonged to an individual who had attended and completed the NAEST management course one week prior to completing the simulator exercises. Should training for situational awareness be updated and reassessed regularly, the individual may display greater signs of observation and vigilance throughout their bridge watch routine.

\section{Conclusion}

The aim of the research conducted in this paper was to highlight the elements required to aid the development of situational awareness among seafarers, understand the views of seafarers regarding the human-automation relationship and 
prepare seafarers for the change to autonomous maritime operations. To accomplish these aims, a study was undertaken which analysed data collected through testing and field research. The results of this study have found that from a pool of participants, containing 14 qualified navigational officers and 14 soon to be qualified officers, over $50 \%$ failed to use alarms, visual cues or prompts to correctly identify a navigational fault.

As highlighted in Table 1, there are advantages and disadvantages to conducting simulator testing. One potential issue with an experiment such as this could be the overall time limit of the exercises. It can be argued that if participants were given a longer period of time to react to an issue, then it may be possible that they could correct it. However, a counter to that would be that malfunctions are not regular and tend to crop up at the most inopportune of times. Furthermore, an error such as this may appear at any point throughout an officer's watch.

As the maritime industry begins to implement autonomous technology on board, further navigational officer training is essential. With human factors being the leading cause of maritime accidents, it is crucial that the industry develops a method of training that will help flatten the learning curve and enhance the knowledge and risks associated with human factors among seafarers.

The introduction of autonomy may bring a new method of learning and training to the maritime industry. Therefore, it is crucial for the maritime industry to listen to the seafarers and officers that will be operating this equipment. An intriguing outcome from this study would be to develop a further simulator study, to be run at a later date, encompassing a longer exercise time and a larger pool of participants. This then could aid the industry and help answer questions on how seafarers would respond in time critical circumstances.

With autonomous operations, it is crucial that operators have the knowledge and acumen to be aware of automation bias and complacency and the influencing factors of human input. As seen from this study, more than half of the participants displayed signs of trust in the autopilot despite acknowledging various cues such as the vessel's position altering and the sounding of the off track alarm, highlighting that seafarers require additional training to help develop and enhance their situational awareness to ensure that they are equipped with the skills and knowledge should they experience situations such as this on watch.

Acknowledgements The authors would like to the staff of South Shields Marine School at South Tyneside College for providing access to student seafarers and for allowing this experiment to be completed using their simulator testing facilities.

Funding PhD research funding given to corresponding author by EPSRC.

Data Availability Not applicable.

Code availability Not applicable.

\section{Declarations}

Conflict of interest The authors declare no competing interests. 
Open Access This article is licensed under a Creative Commons Attribution 4.0 International License, which permits use, sharing, adaptation, distribution and reproduction in any medium or format, as long as you give appropriate credit to the original author(s) and the source, provide a link to the Creative Commons licence, and indicate if changes were made. The images or other third party material in this article are included in the article's Creative Commons licence, unless indicated otherwise in a credit line to the material. If material is not included in the article's Creative Commons licence and your intended use is not permitted by statutory regulation or exceeds the permitted use, you will need to obtain permission directly from the copyright holder. To view a copy of this licence, visit http://creativecommons.org/licen ses/by/4.0/.

\section{References}

ATSB, 2018. Grounding of the landing craft Lauren Hansen, s.1.: Australian Government

Batchelder WH, Narens L (1977) A Critical examination of the analysis of dichotomous data. Philosophy of Science 44:113-135

Bolbot V et al (2020) Paving the way toward autonomous shipping development for european waters The AUTOSHIP Project. Royal Institute of Naval Architects, London

Brown JD (2011). Likert items and scales of measurements? SHIKEN: JALT Testing \& Evaluation SIG Newsletter, 15(1), 10-14

Chyung SY, Roberts K, Swanson I, Hankinson A (2017) Evidence-based survey design: the use of a midpoint on the Likert scale. Perform Improv 56(10):15-23

DNV GL (2017) The ReVolt - a new inspirational ship concept. [Online] Available at: RefSource>https:// www.dnvgl.com/technology-innovation/revolt/index.html[Accessed 19 August 2020]

Eda H, Guest FE, Puglisi JJ (1996) Twenty years of marine simulator (COARF) operations: Lessons learned during these years, 1st edn. Routledge, s.l.

EMSA (2019) Annual overview of marine casualties and incidents 2019, s.1.: European Maritime Safety Agency

Endsley MR (1995) Toward a theory of situation awareness in dynamic systems. Hum Factors 37(1):32-64

Gombolay M, Bair A, Huang C, Shah J (2017) Computational design of mixed-initiative human-robot teaming that considers human factors: situational awareness, workload, and workflow preferences. The International Journal of Robotics Research 36(5-7):597-617

Gregory A, Hogg G, Ker JS (2015) Innovative teaching in situational awareness. Clin Teach 12(5):1-5

Jokioinen E (2016) Advanced autonomous waterborne applications (AAWA) initiative, Rolls-Royce Marine MESA's “The Connected Ship and Shipping." Rolls Royce, Brussels

Kim M, Joung T-H, Jeong B, Park H-S (2020) Autonomous shipping and its impact on regulations, technologies and industries. Journal of International Maritime Safety, Environmental Affairs, and Shipping 4(2):17-25

Kongsberg, 2017. Yara and Kongsberg enter into partnership to build world's first autonomous and zero emissions ship. [Online] Available at:https://www.kongsberg.com/maritime/about-us/news-andmedia/news-archive/2017/yara-and-kongsberg-enter-into-partnership-to-build-worlds-first-auton omous-and/?OpenDocument=

Kretschmann L, Burmeister H-C, Jahn C (2017) Analyzing the economic benefit of unmanned autonomous ships: an exploratory cost-comparison between an autonomous and a conventional bulk carrier. Res Transp Bus Manag 25:76-86

Landman A et al (2018) Training pilots for unexpected events: a simulator study on the advantage of unpredictable and variable scenarios. Hum Factors 60(6):793-805

Lloyds Register, 2019. ShipRight design and construction digital ships: procedure for assignment of digital descriptive notes for autonomous and remote access ships, s.1.: Lloyds Register

Lützhöft MH, Brown P, Dunham R, van Leeuwen WMA (2017) Martime Research. In: M. S. Young \& M. G. Lenné, eds. Simulators for transportation human factors. s.1.:CRC Press, pp. 258-278

MAIB (2017) Grounding of the general cargo vessel Ruyter, s.1.: Marine Accident Investigation Branch

MAIB (2019) Report on the investigation of the grounding of the general cargo vessel Priscilla on Pentland Skerries, Pentland Firth, Scotland on 18 July 2018, s.1.: MAIB 
Marine Insight (2019) 12 International Mobile SIM Cards for Seafarers And Globetrotters. [Online] Available at: https://www.marineinsight.com/life-at-sea/5-international-mobile-sim-cards-for-seafa rers/ [Accessed 15 April 2020]

Maritime UK (2018) Being a responsible industry: maritime autonomous surface ships UK code of practice, s.l.: Maritime UK

MCA (2006) MGN 315 (M) Keeping a safe navigational watch on merchant vessels. [Online] Available at: https://assets.publishing.service.gov.uk/government/uploads/system/uploads/attachment_data/ file/844513/MGN_315.pdf [Accessed 23 January 2020]

MCA (2015) Training \& certification guidance: UK requirements for master and deck officers MSN 1856 $(M+F)$. [Online] Available at: https://assets.publishing.service.gov.uk/government/uploads/system/ uploads/attachment_data/file/436503/MSN1856.pdf [Accessed 23 September 2020]

MCA, 2019. NAEST operational and management-MCA approved training providers. [Online] Available at: https://assets.publishing.service.gov.uk/government/uploads/system/uploads/attachment_data/ file/831492/NAEST_O_and_M_11.11.2019.pdf [Accessed 25 May 2020]

MIT - Marine Casualties Investigative Body, 2012. Costa Concordia Report on the safety technical investigation, s.1.: Ministry of Infrastructures and Transports

Mosier KL et al (2013) Automation, task, and context features: impacts on pilots' judgments of humanautomation interaction. Journal of Cognitive Engineering and Decision Making 7(4):377-399

MSC - IMO (2018) 100th Session, Agenda Item 5: regulatory scoping exercise for the use of maritime autonomous surface ships (MASS), s.1.: International Maritime Organisation

IMO MSC 99 Meeting summary, London: Liberian Registry

MUNIN, 2017. Research in maritime autonomous systems: project results and technology potentials, s.1.: Maritime Unmanned Navigation Through Intelligence in Networks

NYK Line (2019) NYK conducts world's first maritime autonomous surface ships trial. [Online] Available at: https://www.nyk.com/english/news/2019/20190930_01.html [Accessed 14 October 2019]

Parasuraman R, Manzey DH (2010) Complacency and bias in human use of automation: an attentional integration. Hum Factors 52(3):381-410

Pazouki K, Forbes N, Norman RA, Woodward MD (2018) Investigation on the impact of human-automation interaction in maritime operations. Ocean Eng 153(1):297-304

Roberts SE, Nielsen D, Kotłowski A, Jaremin B (2014) Fatal accidents and injuries among merchant seafarers worldwide. Occup Med 64:259-266

Schröder-Hinrichs J-U et al (2013) Maritime human factors and IMO policy. Marit Policy Manag 40(3):243-260

Schuffel H, Boer JPA, van Breda L (1989) The ship's wheelhouse of the nineties: the navigation performance and mental workload of the officer of the watch. J Navig 42(1):60-72

Skitka LJ, Mosier KL, Burdick M (1999) Does automation bias decision-making? International Journal or Human-Computer Studies 51:991-1006

Young MS, Stanton NA (2002) Attention and automation: new perspectives on mental underload and performance. Theor Issues Ergon Sci 3(2):178-194

Publisher's Note Springer Nature remains neutral with regard to jurisdictional claims in published maps and institutional affiliations. 